\title{
A Cost Model for Services
}

\author{
Jürgen Dorn and Wolfgang Seiringer \\ Vienna University of Technology, Institute for Software Technology and Interactive Systems, \\ Favoritenstr. 16, A-1040 Vienna, Austria \\ juergen.dorn@ec.tuwien.ac.at, wolfgang@seiringer.info
}

\begin{abstract}
Typically, services are co-created by service provider and customer. This paper describes an approach to account the full costs of a service considering costs at the provider side as well as on the customer side resulting in a more accurate cost model. Depending on the level of integration of provider and customer, explicit modeling of uncertainty is used to reflect the uncertainty about customer's competences. This model may help to improve the efficiency of services and whole service systems. We evaluate the model in a scenario derived from an industrial application.
\end{abstract}

Keywords: service science, service costs, accounting, cost modeling.

\section{Introduction}

The share of the service sector in most economies is growing, however, the productivity is typically much lower than in the first two economic sectors (i.e. agriculture and manufacturing). Service science tries to understand and to address services to improve the productivity in this sector and to facilitate the innovation of services [1]. A service system is the main abstraction in service science to investigate phenomena in service science [2].

Motivated by the growing importance of services, Vargo and Lusch propose Service-Dominant logic in contrast to traditional goods logic [3]. Regardless of the economic importance of services, a goods-centered view (Goods-Dominant (G-D) Logic) was the predominant concept when thinking about economic exchange. In GD Logic goods are playing the central role of economic exchange while services are just a special form of goods; but services are more than this. This fact is considered in the concept of Service-Dominant (S-D) Logic where every company is seen as a service company and where always services are exchanged [2]. In the goods-centered view, the production of goods is separated from the consumption of goods to maximize the production output [4]. Such a separation is contrary to customeroriented marketing as well as the S-D Logic [5]. This means that the service consumer is actively participating in the process of service co-creation by providing external activities [6]. The traditional logic is based on the exchange of goods or respectively the exchange of goods for money. If a good is sold from a provider to a customer it is already produced, potentially stored in a warehouse and, conceptually, the transaction of exchanging good and money can take place at single points of time. Such a 
transaction can be modeled easily in a state-based knowledge representation. If we do not assume the two actions to occur at the same time, we have three states and two state changes as illustrated by Fig. 1 .

In a conceptual accounting framework such as REA (Resources, Events and Agents) [7] two events (in Fig 1 deliver and pay) are modeled when two agents exchange resources. If this accounting is done in real-time, an agent can determine at any time the amount of its resources (money and goods) by a simple database operation. Proponents of REA claim that with such a computational model, traditional financial balance computation is obsolete because no double entry accounting is necessary [8].

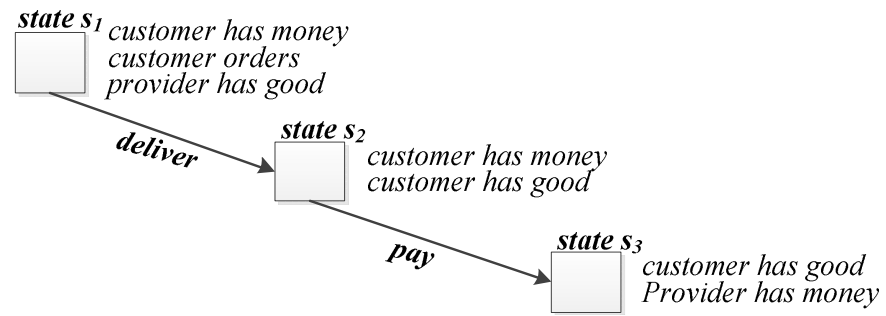

Fig. 1. State-based Representation

However, services are different to goods in several aspects. Service exchange is not occurring in a single point of time, but is a process that takes some time. Services are co-created by provider and customer. Thus, also the customer has to invest at least time and effort in its production. If the customer is a company with employees of different degree of competences and an employee is needed for the service consumption, the success and the efficiency of a service provision is also dependent on the selected employee at the customer side.

The provider makes only a value offering to the customer. If we account costs of services, we have to consider costs at both sides: at the provider and the customer side. If we only want to estimate at which price a provider shall offer a service, we might consider only costs at the provider side. However, if we want to sell services we have to compare different value offerings on the market and then we have to compare full prices including the cost for the customer, because the customer has to consider the offered price and its own costs in co-creation of the service.

S-D Logic claims competences to be the most important resources in services. Thus, we especially have to account the costs of human resources and need a cost model for levels of competences. If an expert is required for a service, the service is more expensive than a service for which only a novice is required.

Our research goal is a model to estimate service costs before service provision (pre-calculation) as well as for computing the real costs afterwards (post-calculation). The model enables: 
- more accurate modeling of costs resulting in a better control of the efficiency of services and a comparable rating of service costs for customers and services.

- measuring true costs for customers, and

- measuring true costs in a complex service system where agents work together to provide services to customers outside of the system.

To evaluate our model we have to compare cost estimations of existing costing systems $c_{t}$ with our approach $c_{s}$ and both of course have to be compared with real costs $c_{r}$.

In the next section we present current theory about services and service cost modeling. In the third section we present a scenario for a typical service. In the fourth section we introduce our model. In the fifth section we describe our evaluation results derived from the application of the CMFS to existing services. Finally we summarize and conclude.

\section{State of the Art}

As mentioned in the introduction compared to goods it is said that services have some special characteristics. These are inseparability, perishability, heterogeneity and uncertainty [9]. Inseparability describes the simultaneous production or as we call it co-creation and consumption of services. The customer defines when the process of service co-creation starts and when the customer is needed by the provider during the co-creation process. The term co-creation is more suited to characterize the processoriented service concept that the value of a service is co-created between the service consumer und the service provider. Perishability describes the fact that a service is not storable. This implies complications to plan resources for the service production. Human resources are the most important resource and cost factor in the context of services. The heterogeneous nature of services makes it difficult to standardize the process of service co-creation because services are often demanded only once.

The process of service co-creation depends on the factors customer integration and external factor and reflects the integrative nature of services. The service co-creation can be separated into the areas of production factors, factor combination and output. The production factors are all the 'objects' which are necessary to produce a service. A production factor can be something tangible or intangible, for example a defective device, information or even the customer himself. The internal production factors are those factors that are provided by the service provider and the external production factor is supplied by the service consumer. It is not possible for the service producer to produce or buy the external factor. Consequently, the external factor and the associated knowledge are under control by the customer. The service provider is forced to integrate it into the service co-creation in form of external activities. During the co-creation, the internal and external production factors are combined (factor combination) to form the tangible or intangible service output [10], [11]. 
In SMEs in manufacturing typically surcharge calculation is common practice to calculate costs. Fixed or variable percentages are added to the costs of materials and labor to determine the production costs [12]. The costs of services as part of a physical product like a product service system (PSS) are often only estimated [13].

A well known costing method is Activity-Based Costing (ABC) which is also used for the cost calculation of services and has its origin in the manufacturing sector. Based on the activities performed in a company, the activities and business processes are identified and analyzed. The total costs for the selected activities are computed by considering the required personnel resources and the salaries. Due to the similarity between overhead costs and service costs, $\mathrm{ABC}$ is also applicable for the service cost calculation. [14].

The implementation and operation of a conventional ABC System is very complex and time-consuming. Thus the Time-Driven Activity-Based Costing (TDABC) was developed. The basic idea underlying this concept is the analysis of the activities performed by the employees and is the same as in the traditional $\mathrm{ABC}$ concept. But to make the implementation and operation of such a costing method easier, time equations are playing a major role. Time is regarded as the leading cost driver because most of the supplied and consumed resources like employees and machines can be measured using the factor time [15]. However, neither ABC nor TDABC cover the external activities (i.e. the activities performed by the customer) and the uncertainty in their performance. The amount of the required human resources depends directly on the external activities. This implies that without the integration of them, a major costinfluencing factor is not being taken into account. This decreases the reliability and the value of service cost information.

\section{Scenario Maintenance Service}

We have applied and evaluated our approach in two scenarios derived from a manufacturing company and a software company. In this paper we present only the first scenario due to space limitations. The manufacturing company produces medical machines and equipment mainly on demand. Today, they have to provide more product-enhancing services then before due to a strong competition. However, the sales department has problems in forecasting costs for these services. Due to specific characteristics of services, the usage of costing methods designed for the usage with materials and goods require a dedicated model. If a service, such as maintenance is offered, the service provision is highly dependent on the customer. If a customer can specify problems accurately and may provide his own experts during maintenance work, the effort for a provider is smaller than for the case that the customer cannot support the service. In the following we model an abstract maintenance process for the manufacturer. The two lanes in the BPMN-diagram represent the two agents (customer and service provider). Both agents exchange information and knowledge at certain points of time. In marketing management these contact points are called touch points. They will be parameterized in our approach to calculate costs. 


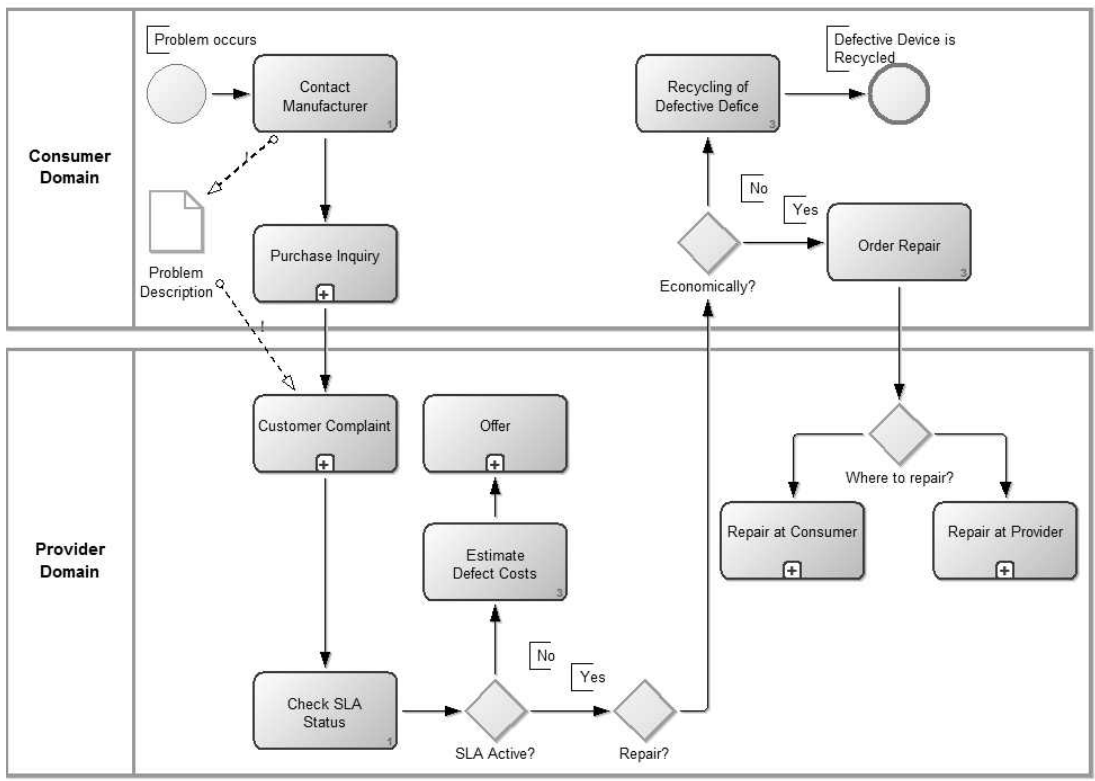

Fig. 2. Prototypical Maintenance Process - Step Check Status of Service Level Agreement (SLA)

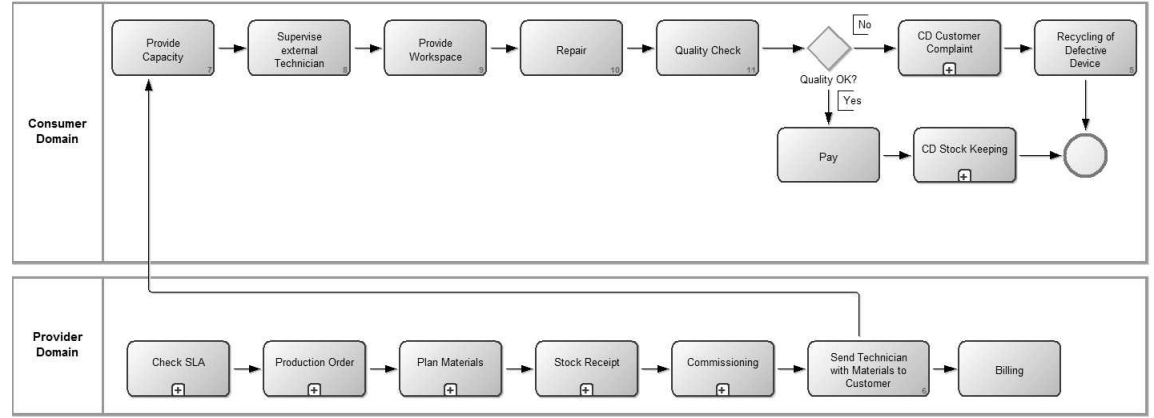

Fig. 3. Prototypical Maintenance Process - Variant Repair at Consumer Domain

The maintenance process starts with the step of checking the Service Level Agreement (SLA). Based on the result of the SLA check step the consumer or provider has to pay for the maintenance service, see also Fig. 2. During the maintenance process different activities carried out on the customer side are e.g. "provide capacity", "supervise external technician", "prepare workspace", "repair", "quality check", "customer complaint", "recycling of defective device", "pay" and "stock keeping". When the customer has to pay for the maintenance two decisions are made on the customer's side. First, the offer of the provider has to be accepted and secondly, the repair must be accepted. The provider activities consist of "check SLA", "production order", "plan materials", "stock receipt", "commissioning", "send 
technician with materials to customer" and "billing", see also Fig. 3. All these activities are dependent on the involvement of the customer. If the customer has not specified the problem correctly much more effort is required at the provider side. The repair can require much more time then estimated, an activity can be carried out several times or can also be skipped. Some activities consist of different sub-activities e.g. "production order" or "stock keeping".

\section{The Model}

A service $(\mathrm{S})$ is produced by a business process (BP) consisting of a set of activities $\left(\mathrm{A}_{\mathrm{i}}\right)$ carried out to fulfill customer satisfaction with a tangible or intangible output. Certain activities depend on the customer. These external activities are not under control of the provider and thus uncertainty about the performance and the service costs has to be considered. Compared to our maintenance scenario the customer provides the defective device, information about the defect and different employees with different competencies. The service provider must integrate these costs influencing external activities during the service co-creation.

Using the activities as the smallest unit, allows the identification of service costs. To calculate the costs for an activity, a time equation is created estimating the time required to carry out this activity. This step is analog to TDABC where the time equation for a service is the sum of all activities of the process realizing the service: $\mathrm{A}_{1}+\ldots+\mathrm{A}_{\mathrm{m}}$. Time is used because it is possible and relatively easy to calculate the consumed resources of humans and machines. For services, human resources are the most important cost factor [15].

Our Cost Model for Services (CMFS) integrates the external activities of the customer by a Customer Integration Factor (CIF) classifying and expressing the uncertainty of the external activities during the process of service co-creation. A central point of the CMFS is the correlation between the CIF and the service activities, see Fig. 4. The value of the CIF parameter is designed to be independent from an activity but is related to it and is used to measure the customer influence on the activity utilization. The pre-calculated activity utilization represents the expected resource consumption and consequently the costs for an activity. The sum of the involved activities corresponds to the pre-calculated service costs. During service cocreation, data about the performed activities are recorded from which the real value of

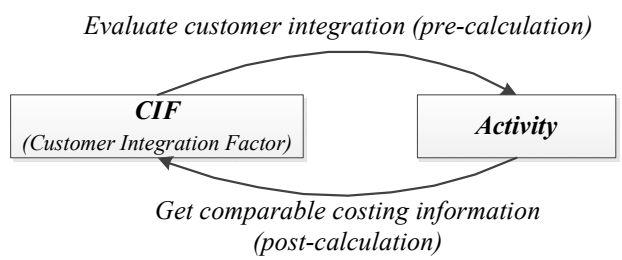

Fig. 4. Correlation between the CIF and service activities 
the CIF parameter and activity utilization can be derived. The recorded data are used to make a post-calculation of the real service costs. The results of the pre- and postcalculation can then be compared and represent valuable costing information, see Fig. 5.

The CIF consists of the parameters influence depth (Idep), influence intensity (Iint), influence frequency (Ifre) and influence duration (Idur). Influence depth (Idep) measures how deep external activities are integrated into the value chain of the service provider. Iint quantifies how intensive a resource will be utilized. The Idep and Iint parameters of the CIF are combined to the Customer Utilization Factor (CUF) to get a special parameter which characterizes the potential capacity utilization for an activity. The influence frequency Ifre indicates how often external activities are part of the service production. The influence duration is used to evaluate how long additional external activities are part of the service co-creation. Resource costs are mainly the costs of the human resources depending on the type of the resource (i.e. expert or novice). The CMFS extends the basic TBABC formula to integrate the CIF parameter and we consider that the knowledge about the external activities is often vague and not precise. This assumption is based on service characteristics which complicate the standardization of the process of service co-creation and the dependency on the external factor which is not under full control of the service provider. As a consequence and to simplify the CIF rating simple linguistic variables are used to classify the four cost effecting parameters of the CIF. In the CMFS a Linguistic Varialbe $L v_{i}, i=1, \ldots, o$ maps values like very low, low, medium, high,... to double values. The central formula of the CMFS is:

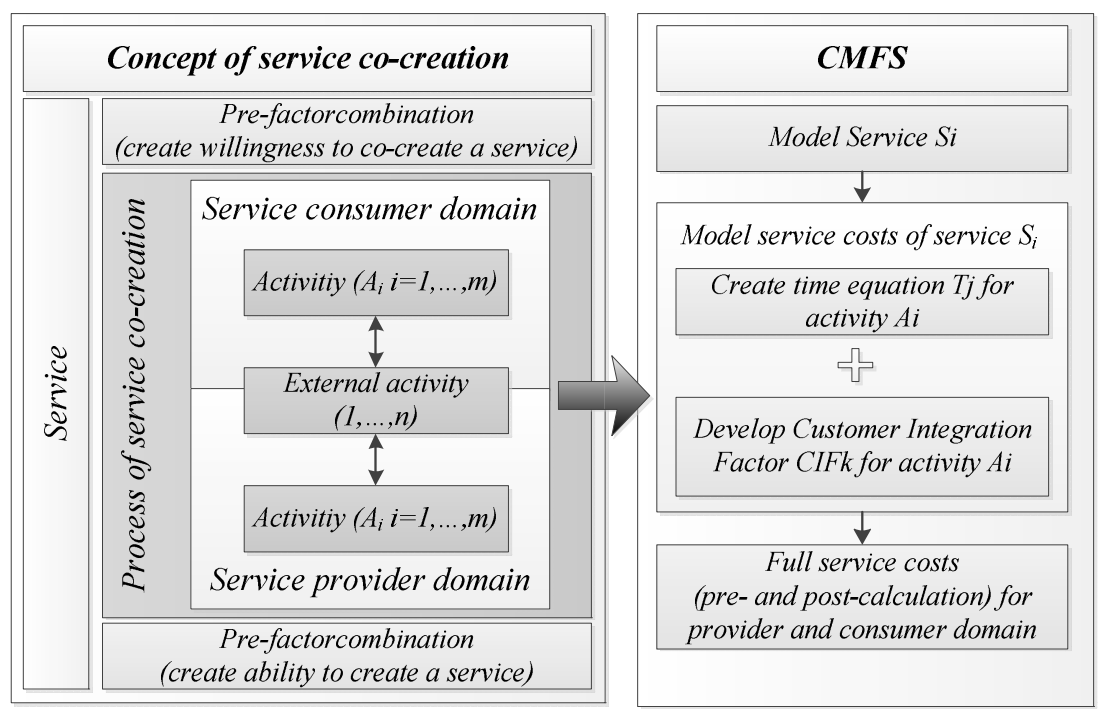

Fig. 5. Concept and components of the Cost Model for Services (CMFS) 


$$
S_{i}=\sum_{i=1}^{m}\left(A_{0 A_{i}}+A_{i}\right) *\left(\left(\operatorname{Idep}_{A_{i}} * \operatorname{Iint}_{A_{i}}\right) * \operatorname{Ifre}_{A_{i}}\right)+\operatorname{Idur}_{A_{i}}
$$

where the variables have the following meaning:

$$
\text { StandardActivityTime: } A_{0 A_{i}}, \text { Services } S_{i}, i=1, \ldots, m, \text { Activies } A_{i}, i=1, \ldots, n
$$

Formula 1: Basic formula and variables of the CMFS to calculate the activity time

The same formula is used for the pre- and post-calculation of the service costs which allows the comparison of the results for the purpose of cost accounting. For the postcalculation, the real amount of consumed resources is accounted during the service co-creation. The required data are service process, activity, start time, end time and employee type. This data can then be assigned to the co-created service and a postcalculation using the same cost model is possible.

\section{Evaluation}

To evaluate the costing method we analyzed the maintenance service of a manufacturing company and the concept development service of a software company. For both examples we have analyzed over 60 different activities, 60 different time equations and over 100 different cost drivers. The amount of activities, cost drivers and time equations depends on the modeled service. For example in the maintenance service, the check SLA step consists of five activities and sub-processes. For each time equation per activity at least one cost driver is necessary. The first evaluation objective is the applicability to different types of business domains, services, business processes and activities. With the second evaluation point we want to find out if the application of the CMFS leads to "realistic" and useful results. The third objective is whether the CMFS parameters can be used to control a complete business process and whether the effects are measurable. The fourth objective treats the traceability of the difference between the CMFS approach and standard TDABC.

\subsection{Result Discussion}

The positive application of the CMFS to services of a manufacturer and a software company show that our approach is not only applicable for a specific business domain. We can argue this with realistic service cost results for each service and company and the CMFS provides new and valuable costing information. For the concept development service which consists of the process steps and activity times "create concept" 2.94 hours, , "document requirements" 3.30 hours, "check and estimate concept" 0.08 hours, "release concept" 0.93 hours, "create offer" 0.25 hours, "create sales order" 0.17 hours, "create forecast" 0.17 hours and "customer domain document requirements" 3.60 hours the service time is 11.43 hours. This is a reasonable result for the investigated company. Also for the maintenance/repair 
service the application of the CMFS leads to realistic and reasonable results, see Fig. 6. With these results our first two evaluation objectives are answered positive. An exemplary time equation for the sales process activity "create offer" as part of the maintenance service is shown in Table 1. This example illustrates the application of the CMFS on a single activity as part of a business process and that it is also possible to influence and the costs of the related business process. It is also possible to trace the costs to its origin. This allows us to answer the third evaluation objective positive. Please note that in the formula of Table 1 the linguistic variables for the CMFS parameters are substituted by real numbers used for computation. The fourth evaluation objective can also be answered positive because the CMFS is a completely independent addition to the TDABC concept which allows tracing and calculating the difference between the CMFS and TDABC results, see also Fig. 6.

Table 1. Example for pre- and post-calculation formula $(\mathrm{m}=$ minutes, $\mathrm{u}=$ units $)$

\begin{tabular}{|l|}
\hline pre-calculation formula \\
\hline$(15 \mathrm{~m}+(500 \mathrm{u} * 0,05 \mathrm{~m}) / 400 \mathrm{u}) * \mathrm{CIF}((\operatorname{CUF}(\operatorname{Idep}(0,75) * \operatorname{Iint}(1)) * \operatorname{Ifre}(0,5))+\operatorname{Idur}(0)=5.65$ \\
Minutes \\
\hline post-calculation formula \\
\hline $54 \mathrm{~m} * \mathrm{CIF}(\mathrm{CUF}(\operatorname{Idep}(0,1) * \operatorname{Iint}(0,057)) * \operatorname{Ifre}(3))+\operatorname{Idur}(30)=30.92$ Minutes \\
\hline
\end{tabular}

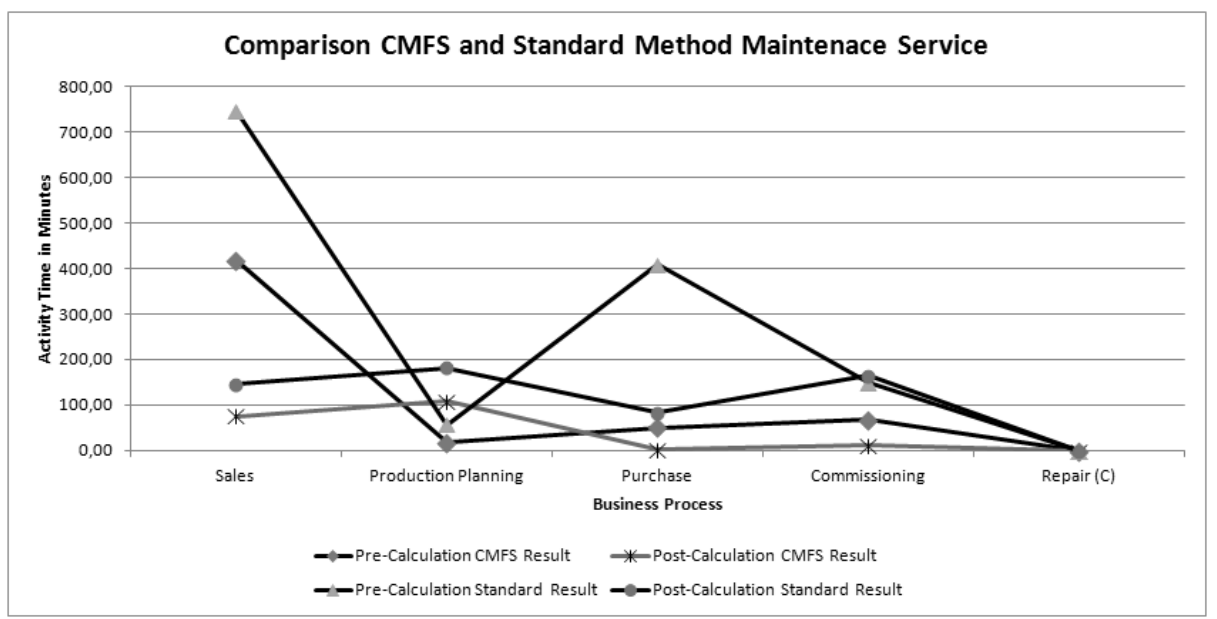

Fig. 6. Comparison of pre- and post-calculation results - maintenance service

\section{Conclusions}

Service systems are system configurations where actors cooperate in order to provide services to other service systems. On one side the cooperation in the service system demands win-win relations between providers and customers and on the other side service marketing demands a similar relation between provider and customer. Consequently, we ask for a cost modeling approach that takes into account costs at 
both sides. Especially for services the most important cost driving factor are personal costs. The competence of both actors in the service provision process is most important for the quality and efficiency of a service. Additionally, the uncertainty about the customer's behavior is a relevant factor in any cost model applied by a provider.

We have analyzed the service costs at real companies and made computations with a new model that considers these problems. Computations for prototypical services have shown that we can reach in average a higher accuracy (about 10-30\%) in forecasting of service costs than with the current cost models at these companies. This first evaluation must, however, be repeated in the actual practice with more historical data and compared with actual costs. Here we have to evaluate whether the difference between forecasted and actual costs are really smaller than our first evaluation has shown. We conclude from our evaluations that it is possible to parameterize the CMFS from complex services to a single activity and that the CMFS is easily adaptable for different service scenarios and business domains. The standard activity time $A_{i}$ has strong influence on the results and the entire model depends on many different parameters especially from the TDABC approach.

A next step in our research is to investigate how our approach can be integrated most efficiently in an enterprise resource planning (ERP) system. Here additional information about customers has to be managed and the integration with human resources data has to be realized. We also plan to carry out additional statistical analysis of evaluation results to refine our approach.

\section{References}

1. Spohrer, J., Maglio, P., Bailey, J., Gruhl, D.: Steps Toward a Science of Service Systems. IEEE Computer, 71-77 (January 2007)

2. Vargo, S.L., Lusch, R.F.: Evolving to a new Dominant Logic for Marketing. Journal of Marketing 68, 1-17 (2004)

3. Spohrer, J., Vargo, S., Caswell, N., Maglio: The Service System is the Basic Abstraction of Service Science. In: Proceedings of the 41st Hawaii International Conference on System Sciences (2008)

4. Lusch, R., Vargo, S.: Service-Dominant Logic: What It Is, What It Is Not, What It Might Be. In: The Service-Dominant Logic of Marketing: Dialog, Debate, and Directions, pp. 43-56. M.E. Sharp, New York (2006) ISBN 0-7656-1490-1

5. Lusch, R., Vargo, S.: Service-dominant logic: reactions, reflections and refinements. Marketing Theory 6(3), 281-288 (2006)

6. Wattanakamolchai, S.: Managing Customer Participation in the Service Production Process (2009)

7. Geerts, G.L., McCarthy, W.E.: An Ontological Analysis of the Economic Primitives of the Extended-REA Enterprise Information Architecture. International Journal of Accounting Information Systems 3, 1-16 (2002)

8. McCarthy, W.E.: The REA Accounting Model: A Generalized Framework for Accounting Systems in A Shared Data Environment. The Accounting Review, 554-578 (1982) 
9. de Vries, W., Kasper, H., van Helsdingen, P.: Service Marketing Management - An International Perpective, pp. 8-20. John Wiley \& Sons, West Sussex (1999) ISBN 0-47198490-6

10. Frisch, R.: Theory of Production, pp. 3-5. Springer, Netherlands (2009) ISBN 9789048183340

11. Flandel, G., Blaga, S.: Elements of the production of services. In: Modern Concepts of the Theory of the Firm - Managing Enterprises of the New Economy, pp. 175-189. Springer, Heidelberg (2004)

12. Myers, J.: Traditional versus activity-based product costing methods: a field study in a defense electronics manufacturing company. Proceedings of ASBBS 16(1) (2009)

13. Mont, O.K.: Clarifying the concept of product-service system. Journal of Cleaner Production 10, 234-245 (2002)

14. Cooper, R., Kaplan, R.S.: Measure Costs Right: Make the Right Decisions. Harvard Business Review (1988)

15. Anderson, S.R., Kaplan, R.S.: Time-Driven Activity-Based Costing: A Simpler and More Powerful Path to Higher Profits. Mcgraw-Hill Professional (2007) ISBN 978-1422101711 